\title{
Insulin treatment and high-fat diet feeding reduces the expression of three Tcf genes in rodent pancreas
}

\author{
Joshua Columbus ${ }^{1,2}$, YuTing Chiang ${ }^{1,2}$, Weijuan Shao ${ }^{2}$, Nina Zhang ${ }^{1,3}$, Dingyan Wang², \\ Herbert Y Gaisano ${ }^{1,3}$, Qinghua Wang ${ }^{1,3,4}$, David M Irwin ${ }^{5}$ and Tianru Jin ${ }^{1,2,3,4,5,6}$ \\ ${ }^{1}$ Department of Physiology, University of Toronto, Toronto, Ontario, Canada M5S 1A8 \\ ${ }^{2}$ Division of Cell and Molecular Biology, Toronto General Research Institute, University Health Network, 10-354 Toronto Medical Discovery Tower, The MaRS \\ Building, 101 College Street, Toronto, Ontario, Canada M5G 1L7 \\ ${ }^{3}$ Department of Medicine, University of Toronto, Toronto, Ontario, Canada M5S 1A8 \\ ${ }^{4}$ Division of Endocrinology and Metabolism, The Keenan Research Centre in the Li Ka Shing Knowledge Institute, St Michael's Hospital, Toronto, Ontario, \\ Canada M5B 1W8 \\ ${ }^{5}$ Department of Laboratory Medicine and Pathobiology, Toronto, Ontario, Canada M5S 1A8 \\ ${ }^{6}$ Department of Nutrition, School of Public Health, Sun Yat-Sen University, Guang Zhou 510275, People's Republic of China \\ (Correspondence should be addressed to T Jin at Division of Cell and Molecular Biology, Toronto General Research Institute, University Health Network; \\ Email: tianru.jin@utoronto.ca)
}

\begin{abstract}
Specific single-nucleotide polymorphisms in intronic regions of human TCF7L2 are associated with an elevated risk of developing type 2 diabetes. Whether Tff 712 is expressed in pancreatic islets of rodent species at a considerable level, however, remains controversial. We used RT-PCR and quantitative RT-PCR to examine Tcf7l2 expression in rodent gut, pancreas, isolated pancreatic islets, and cultured cell lines. The expression level of Tcf7l2 was relatively lower in the pancreas compared to the gut or the pancreatic $\beta$-cell line Ins-1. Immunostaining did not detect a Tcf 712 signal in mouse pancreatic islets. Endogenous canonical Wnt activity was not
\end{abstract}

appreciable in the pancreas of TOPGAL transgenic mice. Both Tof7 and Tof7l1, but not Lef1, were expressed in the pancreas. The expression of the three $T c f$ genes ( $T c f 7, T c f 711$, and $T(f 7 / 2)$ in the pancreas was reduced by treatment with insulin or high-fat diet feeding, in contrast to the stimulation of Tcf7l2 expression by insulin in the gut. We suggest that hyperinsulinemia represses $T c f$ gene expression in the pancreas. Whether and how this reduction alters the function of pancreatic $\beta$ cells during hyperinsulinemia deserves further investigation.

Journal of Endocrinology (2010) 207, 77-86

\section{Introduction}

The major effector of the canonical Wnt signaling pathway is the bipartite transcription factor cat/TCF, formed by free $\beta$-catenin ( $\beta$-cat) and a member of the TCF protein family (TCF-1/TCF7, LEF1, TCF-3/TCF7L1, and TCF-4/TCF7L2; Jin 2008). This pathway exerts important physiological and pathological functions in different cell lineages and organs, including organogenesis, tumor development, and metabolic homeostasis (Kinzler \& Vogelstein 1996, He et al. 1998, Jin et al. 2008).

Grant et al. (2006) identified an association between TCF7L2 polymorphisms and the risk of type 2 diabetes mellitus (T2D) among European and American populations. Since then, extensive genome-wide association studies have further confirmed their discovery globally and among ethnically diverse populations (Florez et al. 2006, Munoz et al. 2006, Scott et al. 2006, Cauchi et al. 2007, Dahlgren et al. 2007, Elbein 2007, Sladek et al. 2007, Jin 2008,
Jin \& Liu 2008). Although several investigations have indicated that individuals who carry the risk of TCF7L2 polymorphisms exhibited impaired insulin secretion and enhanced rate of hepatic glucose production (Florez et al. 2006, Lyssenko et al. 2007, Schafer et al. 2007, Kirchhoff et al. 2008), in mouse models and in humans, whether Tcf 712 regulates the function of $\beta$ cells remains controversial (Jin 2008, Liu \& Habener 2008, Krutzfeldt \& Stoffel 2010). $T c f 7 l 2^{-1-}$ mice that were generated more than a decade ago exhibit defects in the development of the gut (Korinek et al. 1998) and abnormal growth of the pituitary (Brinkmeier et al. 2007). However, these investigations did not find expression or function of Tcf 712 in pancreatic islets (Korinek et al. 1998, Brinkmeier et al. 2007). Very recently, Krutzfeldt \& Stoffel (2010) reported that the canonical Wnt signaling pathway is not active in pancreatic islets of adult mice, whereas in two different insulin resistance mouse models, Wnt4 is abundantly expressed, and Wnt4 expression inhibits canonical Wnt signaling in pancreatic islets. 
We show in this study that the expression level of $T c f 712$ is relatively lower in rodent pancreas, compared with the gut. Furthermore, we observed the expression of Tcf 7 and Tof 711 in the pancreas of rodent species. In addition, we found that the expression of Tof7, Tof 711 , and Tof 712 in the rodent pancreas can be significantly downregulated by insulin treatment or high-fat diet (HFD) feeding, in contrast to the stimulation of $T c f 712$ expression by insulin in the adult and fetal gut, as well as in the intestinal endocrine L-cell line GLUTag (Sun et al. 2010). Finally, we have also found a lack of cat/TCF-mediated reporter gene activity in the pancreas of TOPGAL transgenic mice (Krutzfeldt \& Stoffel 2010), even at e12.5 and neonatal stage. These observations collectively suggest that further extensive investigations are required to clarify the role of the $T c f$ genes and Wnt signaling in the function of pancreatic $\beta$ cells.

\section{Materials and Methods}

\section{DNA sequencing}

PCR products were verified by agarose gel electrophoresis, purified, and inserted into TA cloning vectors (Invitrogen). DNA sequences of the inserts were obtained by automatic sequencing. DNA sequences were aligned with the mouse Tcf7l2 sequence from GenBank (NM_001142924) and analyzed with ClustalW2 (EBI) software.

\section{Mice, rat, islet isolation and fetal rat intestinal cell culture preparation}

TOPGAL mice were purchased from Jackson Laboratory (strain name Tg-Fos-lacZ-34Efu/J, stock no. 004623; Bar Harbor, ME, USA). Pancreas, tail, heart, lungs, intestines, neonatal mice, as well as mice at e12.5 were taken for LacZ staining. Briefly, mice were killed, and tissue samples were dissected, washed in cold PBS, and placed in fixing solution ( $0.5 \%$ gluteraldehyde, $0.5 \%$ formaldehyde, $5 \mathrm{mM} \mathrm{EGTA}$, and $2 \mathrm{mM} \mathrm{MgCl} 2$ in PBS at $\mathrm{pH} \mathrm{7 \cdot 3)}$ for $10-20 \mathrm{~min}$. Tissue samples were then washed three times $(15 \mathrm{~min}$ each) with wash buffer $\left(2 \mathrm{mM} \mathrm{MgCl}_{2}, 0 \cdot 01 \%\right.$ sodium deoxycholate, and $0.02 \% \mathrm{NP}-40$ in PBS at $\mathrm{pH} 7 \cdot 3$ ) at room temperature, then placed in staining solution $(1 \mathrm{mg} / \mathrm{ml} \mathrm{X}$-gal, $2 \cdot 12 \mathrm{mg} / \mathrm{ml}$ potassiumferrocyanide, and $1.64 \mathrm{mg} / \mathrm{ml}$ potassium ferricyanide in wash buffer) for $4 \mathrm{~h}$ shaking gently at $37^{\circ} \mathrm{C}$. Nineweek-old $(n=3$, male) adult Wistar rats, weighing $\sim 300 \mathrm{~g}$, were purchased from Charles River (St Laurent, Québec, Canada). Islets isolation was conducted as described earlier (Wang et al. 2009). Briefly, collagenase solution was injected into the pancreas through the common bile duct of the anesthetized rats. The distended pancreas was removed and incubated for $20 \mathrm{~min}$ in a $37^{\circ} \mathrm{C}$ shaking water bath. Islets were separated after four centrifugations and a sedimentation period. The method for the generation of fetal rat intestinal cell (FRIC) cultures has been described elsewhere
(Yi et al. 2008). Briefly, intestines of 3-week gestation fetal Wistar rats were pooled together and incubated with collagenase, hyaluronidase, and DNase I. The dispersed cells were washed and placed into monolayer cultures. Mouse pancreas and gut samples were obtained from 6-week-old male C57BL6 mice $(n=3)$ after being anesthetized. In addition, C57BL6 mice were fed with either HFD or regular chow diet for 2 months ( $n=3$ for each group), and their pancreata were isolated. The generation of hyperinsulinemia and insulin resistance by HFD feeding was monitored by serum insulin detection and intravenous glucose tolerance tests. All animal procedures have been approved by Animal Resource Centre, Toronto General Research Institute, University Health Network.

\section{Cell culture and western blotting}

The mouse large intestine endocrine L-cell line GLUTag (Drucker et al. 1994) and the human colon cancer cell line SW-480 were cultured in DMEM medium (Sigma-Aldrich) as described earlier (Drucker et al. 1994, Sun et al. 2009). Rat pancreatic Ins-1 cell line was grown in RPMI-1640 (SigmaAldrich), supplemented with $10 \% \mathrm{FBS}, 1 \% \mathrm{P} / \mathrm{S}, 1 \mathrm{mM}$ sodium pyruvate, $2 \mathrm{mM}$ L-glutamine, $10 \mathrm{mM}$ HEPES, 0.05 mM 2-mercaptoethanol, and $11 \mathrm{mM}$ glucose. Western blotting was conducted as described earlier (Sirek et al. 2009). Antibodies against TCF7L2 (H-125) [sc-13027] for C-terminal part of the protein and actin (C4) [sc-47778] were the products of Santa Cruz Biotechnology Inc. (Santa Cruz, CA, USA) Approximately, $30 \mu \mathrm{g}$ of total protein was loaded into each lane. A rabbit polyclonal TCF7L2 antibody (SC13027; 1:1000 dilution) was used in this assay.

\section{Immunohistochemistry}

Mouse pancreatic tissues were processed and paraffin embedded as described earlier (Wang \& Brubaker 2002). Triple staining was sequentially performed for insulin, glucagon, and Tcf7l2. The primary antibodies used were guinea pig anti-insulin (Dako, Mississauga, ON, Canada; 1:500), rabbit anti-glucagon (Dako; 1:500), and an antiTCF7L2 antibody (SC8631, Santa Cruz Biotechnology Inc.; 1:200). The staining was visualized by secondary antibodies: FITC-conjugated donkey anti-guinea pig antibodies (Jackson, West Grove, PA, USA; 1:400), Cy3-conjugated donkey anti-rabbit antibodies, and aminomethyl coumarinconjugated donkey anti-mouse antibody (Jackson; 1:200) using a Nikon fluorescence microscope (Eclipse TE 200).

\section{$R N A$ extraction, $R T-P C R$, and real-time $R T-P C R$}

Total RNA was extracted using the Trizol method (Invitrogen Life Technology) according to the manufacturer's protocol. The quality of RNA was verified by agarose gel electrophoresis as described earlier (Jin \& Drucker 1996). Approximately, $2 \mu \mathrm{g}$ of total RNA (OD 260/280 ratio > 1.8) was used for first-strand cDNA synthesis using random 
hexamers and Superscript RT II (Invitorgen Life Technology). PCRs were conducted with a Mastercycler Gradient thermocycler (Eppendrof Scientific Inc., Westbury, NY, USA). Real-time RT-PCR was performed with RotorGene 3000 (Corbett Research, Dorval, Quebec, Canada) using the SYBR Green PCR Master Mix (Applied Biosystems, Foster City, CA, USA) as described earlier (Sun et al. 2009). The relative expression levels were normalized to the expression of $\beta$-actin or glyceraldehyde-3-phosphate dehydrogenase, which were used as internal controls. The relative mRNA transcript levels were calculated according to the $2^{-\Delta \Delta C_{\mathrm{T}}}$ method, in which $\Delta C_{\mathrm{T}}$ represents the difference in threshold cycle values between the target mRNA and the internal control, and $\Delta \Delta C_{\mathrm{T}}$ represents the difference in threshold cycle values between the experimental and the control mRNAs (Sun et al. 2010). All the primers were synthesized by ACGT Corporation (Toronto, Ontario, Canada) and are presented in Table 1. All primers for Tff 712 and the three other $T c f$ family members were designed so that each pair could amplify the corresponding cDNAs from both mouse (NM_001142924) and rat (XM_001072517).

\section{Statistical analysis}

All experiments were conducted at least three times. Results are indicated as the mean \pm S.D., and the statistical significance between two experimental conditions was analyzed by the Student's $t$-test. Differences between groups are considered significant if $P<0 \cdot 05$.

\section{Results}

Design of primers for Tcf712 detection by RT-PCR in mouse pancreas

Tff7l2 $m R N A$ is abundantly expressed in the mouse gut (Korinek et al. 1998), and extensive alternative splicing of the Tff7l2 gene has been documented (Duval et al. 2000b, Shiina et al. 2003, Prokunina-Olsson et al. 2009a,b). Based on these previous reports regarding alternative splicing of mouse Tcf712, and cDNAs and ESTs in the NCBI database, we designed five pairs of primers to portions of the various alternative transcripts (Table 1). The positions of these primers on the exon regions of the gene are illustrated in Fig. 1A. We found that all five pairs of primers could amplify Tcf 712 cDNA from mouse gut, but failed to generate a visible band with cDNA from mouse pancreas (data not shown). We also used these primers with cDNA from the pancreatic $\beta$-cell line Ins-1. Although these primer pairs failed to detect Tof 712 cDNA from the pancreas, all of them could amplify cDNA for Tcf7l2 from the Ins-1 cell line (data not shown). These observations suggested that if rodent pancreas does express Tcf7l2, then the level of expression will be lower than that observed in the gut or in the immortalized $\beta$-cell line Ins-1 (Supplementary Figure 1, see section on supplementary data given at the end of this article).

Next, we conducted RT-PCR using the primer pair 1F and $3 R$, which amplifies sequences from exons 1 to 18 , and the primer pair $1 \mathrm{~F}$ and $5 \mathrm{R}$, which amplifies sequences from

Table 1 Nucleotide sequences of primers used in this study

DNA sequence

\section{Name}

Pair 1

Pair 2

Pair 3

Pair 4

Pair 5

TCF7

TCF7L1

LEF1

Gcg

c-Myc

$\beta$-Actin

GAPDH
1F: 5'-GCT AAC GAC GAG CTG ATC TCC TTC- $3^{\prime}$ 1R: 5'-GTC TAC GTC AGC TGG TAA GTG CGG-3' 2F: 5'-CTG CTT GAT GTC CAA GCA GGA AGC-3' 2R: 5'-GTA CAG CTG CAT GTG AAG CTG TCG-3' 3F: 5'-TGA AAG AGA TGA GAG CGA AGG TGG-3' 3R: 5'-CTA GTA AGC TTC CAT CTG AAG AGG-3' 4F: 5'-GCT AAC GAC GAG CTG ATC TCC TTC-3' 4R: $5^{\prime}$-CCT CAC AAG AAG TCA CAG CGA CTC-3' 5F: 5'-TGA AAG AGA TGA GAG CGA AGG TGG-3' 5R: 5'-ACA TAA GAG TGG TCC TCC AAC CTC-3' F: 5'-AGG TCA GAT GGG TTG GAC TG-3' R: 5'-AGG GTG CAC ACT GGG TTT AG-3' F: $5^{\prime}$-GAG TGC GAA ATC CCC AGT TA-3' R: $5^{\prime}$-ATG CAT GGC TTC TTG CTC TT-3' F: 5'-CTC ATC ACC TAC AGC GAC GA-3' R: 5'-TGA GGC TTC ACG TGC ATT AG-3' F: $5^{\prime}$-GCC CAG GAC ACA CTC AAA GT-3' R: 5'-TGA CGT TTG GCA ATG TTG TT- ${ }^{\prime}$ F: 5'-CAA ATC CTG TAC CTC GTC CG- $3^{\prime}$ R: 5'-GTT GTG CTG GTG AGT GGA GA-3' F: 5'-TCA TGA AGT GTG ACG TTG ACA-3' R: 5'-CCT AGA AGC ATT TGC GGT G-3' F: $5^{\prime}$-TGA AGG TCG GTG TGA ACG GAT TTG GC- $3^{\prime}$ R: 5'-CAT GTA GGC CAT GAG GTC CAC CAC-3'
Anticipated PCR product size $(\mathrm{bp})$ 
A

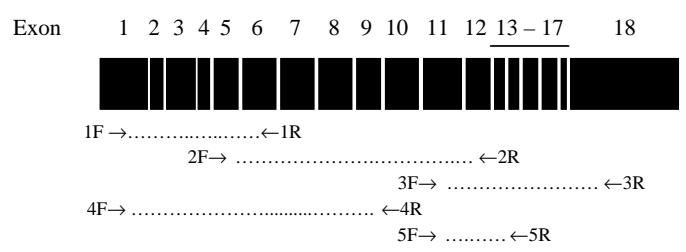

B

Mouse gut

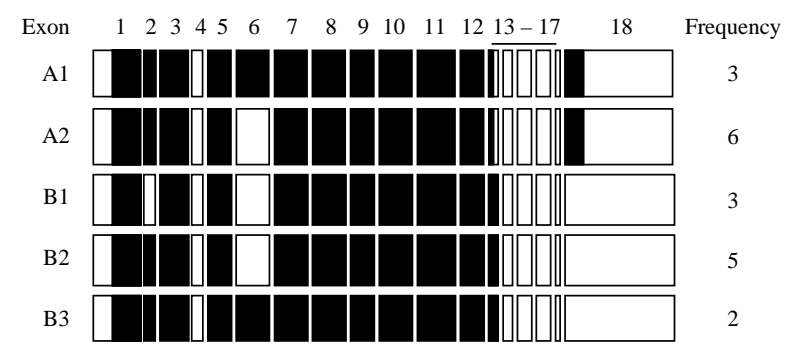

C

Ins-1

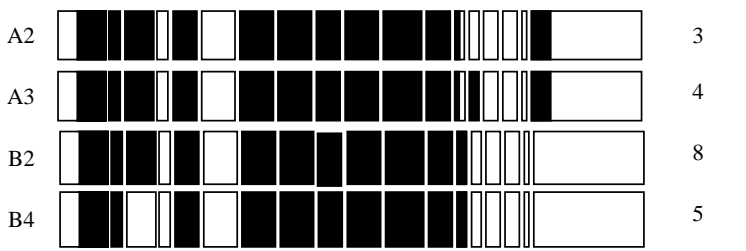

Figure 1 Exon organization of the mouse $T c f>12$ gene and locations of the five pairs of primers. (A) Scheme showing the exon structure of the $T c f>12$ gene. Arrows indicate the positions of the five pairs of primers (detailed in Table 1). Schematic representation of alternatively spliced forms of $T c f 7 / 2$ detected in the (B) mouse gut and the $(C)$ rat pancreatic $\beta$-cell line Ins-1. Isoforms $A 1-A 3$ were detected using the primers $1 \mathrm{~F}$ and $3 \mathrm{R}$, whereas isoforms $\mathrm{B} 1-\mathrm{B} 4$ were detected using the primers $1 \mathrm{~F}$ and $5 \mathrm{R}$.

exons 1 to 13 (Fig. 1A). After sequencing 19 clones, we were able to identify five different alternatively spliced forms of Tcf7l2 expressed in the mouse gut (Fig. 1B). Isoforms A1 and $\mathrm{A} 2$ end in exon 18, whereas isoforms B1, B2, and B3 end in exon 13. The same approach was then applied to the immortalized pancreatic $\beta$-cell line Ins-1, which led to the identification of four isoforms (Fig. 1C) from 20 sequenced clones, including two novel isoforms: A3, which ends in exon 18 but contains exon 14, and B4, which ends in exon 13 but with the deletion of exon 3. Tcf7l2 isoforms A2 and B2 were found in both the gut and Ins-1 cDNA.

Since all of the isoforms that we obtained from Ins-1 cells contain intact exons $8,9,10$, and 11 , we designed a new pair of primers, namely 6F and 6R (Fig. 2A), and used them on cDNA generated from mouse gut and pancreatic tissue and islets. This pair of primers generated a DNA fragment of the anticipated size from gut, pancreatic, and islet cDNA, and was confirmed to be Tcf7l2 by DNA sequencing. Although this $320 \mathrm{bp}$ fragment could be amplified from the gut, the pancreas, and the pancreatic islets cDNA, the intensity of the RT-PCR products from pancreatic tissue and islets was much weaker than those from the gut (Fig. 2B).

\section{Expression of Tcf712 in pancreas and islets is low}

Real-time quantitative RT-PCR (qRT-PCR) was then performed with the new pair of primers with cDNA from mouse gut, pancreas, and islets. As shown in Fig. 2C, the $T c f 7 l 2$ expression level in pancreas and islets is approximately five times lower than that of the gut. Western blotting was then conducted with C-terminal antibody for TCF7L2 and detected a protein that is slightly above the molecular mass of $55 \mathrm{kDa}$, matching the predicted size range of $T$ cf 712 , in the GLUTag, Ins-1, and SW-480 cell lines, as well as in mouse gut (Fig. 2D). Only a very weak band at the corresponding position was detected from the mouse pancreas (Fig. 2D). Densitometric analysis indicates that $\mathrm{Tcf} 712$ protein expression level in the pancreas was $7 \%$ of that detected in the gut. This antibody also detected another protein from the three cell lines and two other proteins from the intestinal tissue that migrated slower than the presumed Tcf 712 band (Fig. 2D). The estimated sizes of these three proteins do not match the predicted sizes of any of the Tcf 712 isoforms identified in Fig. 1. When a Tcf712 antibody was used in immunostaining of mouse pancreatic paraffin sections, we could not detect $T f f 712$ in pancreatic islets (Fig. 2E), which is consistent with our previous observation (Yi et al. 2005). These observations collectively suggest that $T f f 7 l 2$ is not abundantly expressed in the mouse pancreas or in pancreatic islets.

\section{Both Tcf7 and Tcf711 are also expressed in the pancreas}

Considering the suggested role of the Wnt signaling pathway in mouse pancreatic islet development and the lack of abundant expression of $T c f 712$, we examined the expression of the other three members of the Tff family in the rodent gut and pancreas. Primers used in RT-PCR for the detection of expression of the $T f f 7, T f f 711$, and Lef1 genes are shown in Table 1. PCR products were purified, inserted into TA cloning vectors, and verified by DNA sequencing. As shown in Fig. 3 , in addition to $T c f 712$, both $T c f 7$ and $T c f 711$, but not Lef1, were found to be expressed in the mouse (Fig. 3A) and rat (Fig. 3B) pancreas and gut.

Expression of $\mathrm{Tcf} 712$ in pancreatic tissue and islets is downregulated by insulin treatment

A recent study has shown that Tcf7l2 expression in pancreatic islets can be downregulated by hyperinsulinemia, associated with the reduced expression of the incretin hormone receptors (Shu et al. 2009). We, however, have observed that in human and mouse intestinal cell lines, insulin stimulated Tcf7l2 mRNA and protein expression (Sun et al. 2010). To investigate whether insulin affects the expression of $T c f 712$ and other $T f f 7$ family members in rodent 
A

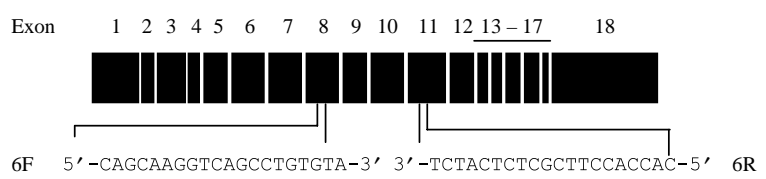

B

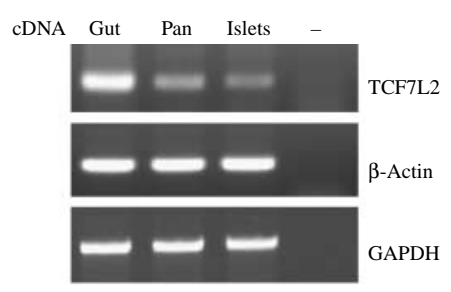

$\mathrm{C}$

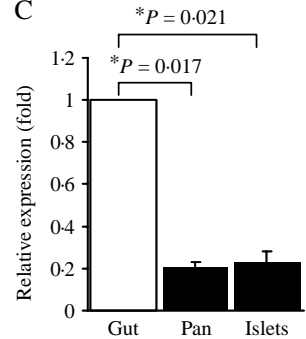

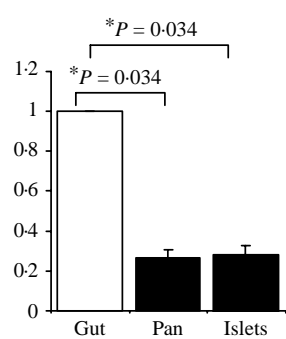

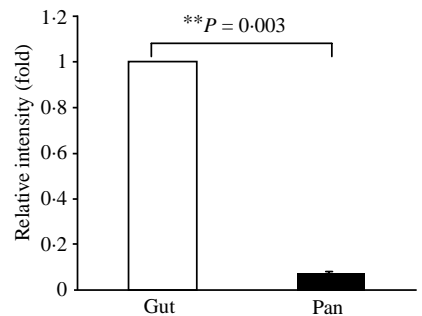

$\mathrm{D}$
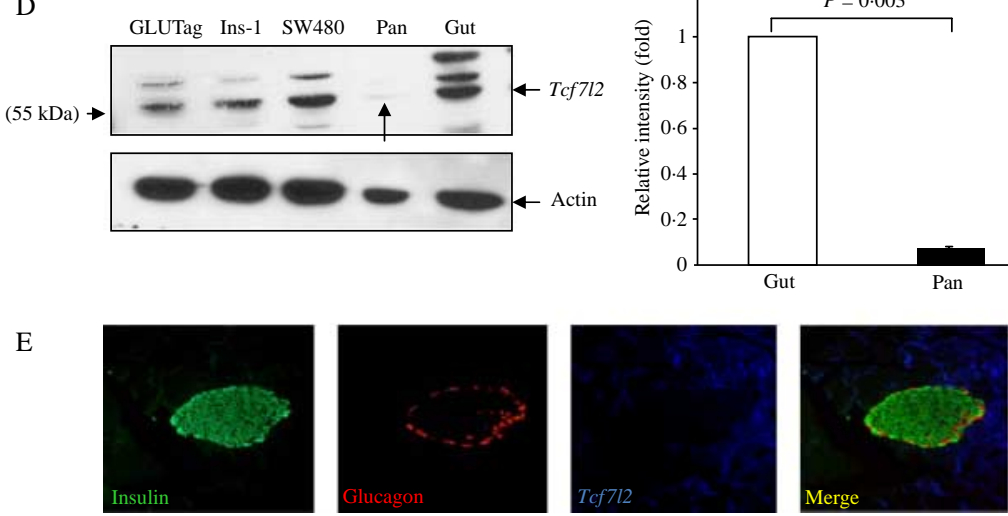

Figure $2 T c f 7 / 2$ expression level is lower in the mouse pancreas. (A) The positions of the primers 6F and 6R. (B) Detection of $T c f 7 / 2$ expression in the mouse gut, the pancreas, and the islets using primers $6 \mathrm{~F}$ and $6 \mathrm{R}$. Both $\beta$-actin and GAPDH were used as loading controls. A representative gel from three experiments is shown. (C) Quantitative RT-PCR assessment of Tcf $7 / 2$ expression in the mouse gut, the pancreas, and the isolated mouse pancreatic islets, using primers $6 \mathrm{~F}$ and $6 \mathrm{R}$. GAPDH (left panel) and $\beta$-actin (right panel) were used as normalization controls. Results are from three independent experiments, with triplicate samples per tissue from one mouse per experiment. (D) Western blotting with C-terminal antibody shows the very low expression level of $T c f>l 2$ in mouse pancreas. A representative blot was shown (left panel), and densitometric graph (right panel) was generated from three independent experiments. (E) Immunohistochemistry of pancreatic section from a 9-week-old male cluster of differentiation 1 mouse stained for insulin (green), glucagon (red), and $T c f 7 / 2$ (blue, C-terminal antibody). ${ }^{*} P<0 \cdot 05 ;{ }^{*} P<0 \cdot 01$. Full colour version of this figure available via http://dx.doi.org/10.1677/JOE-10-0044.

pancreatic islets, we conducted the following investigations. First, we treated both the large and small intestines of the mouse with insulin $(100 \mathrm{nM})$ for $3 \mathrm{~h}$ and assessed the expression of the Tff family members by both RT-PCR and qRT-PCR. Results obtained from both of these methods indicate that $T c f 7 l 2 \mathrm{mRNA}$ expression in the large intestine was significantly increased after insulin treatment; however, the mRNA levels of both $T c f 7$ and $T c f 7 l 1$ were not affected significantly by insulin treatment in the large intestine (Fig. 4A and B). Similar observations were made with the small intestine (Fig. 4C and D). Although an approximately threefold increase in Tcf $712 \mathrm{mRNA}$ expression was observed in the small intestine after insulin treatment, no significant effect of insulin on $T c f 7$ or $T c f 7 l 1$ mRNA expression levels was observed. We then expanded our investigation into FRIC cultures. Freshly prepared FRIC cultures were treated with $100 \mathrm{nM}$ insulin for $3 \mathrm{~h}$, followed by cell harvesting, RNA extraction, RT-PCR, and qRT-PCR. Consistent with our previous report ( $\mathrm{Yi}$ et al. 2008), insulin treatment led to a $2 \cdot 5$-fold increase of proglucagon ( $\mathrm{gcg}$ ) mRNA expression, associated with a threefold increase in expression of c-Myc, a known downstream target of the canonical Wnt signaling pathway, and a twofold increase in Tcf 712 expression (Fig. 5A and $\mathrm{B})$. In contrast, in the pancreas, a $3 \mathrm{~h}$ insulin treatment led to 80,60 , and $80 \%$ reductions in $T$ cf 7 , T $f f 711$, and $T f f 712$ mRNA abundance respectively (Fig. 5C and D). 
A

Mouse

cDNA Pan Gut -

\begin{tabular}{ll}
$=$ & Tef7 \\
\hline- & Tef711 \\
& Lef1 \\
& Tef712 \\
& $\beta$-Actin
\end{tabular}

B

\section{Rat}

cDNA

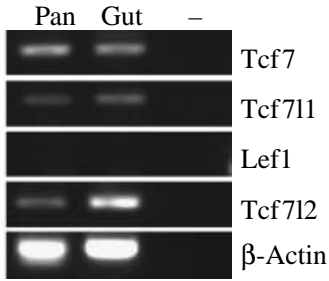

Figure $3 T c f 7$ and $T c f 7 / 1$ are expressed in mouse and rat pancreas. cDNAs from (A) 6-week-old mouse $(n=3)$ or (B) 9-week-old rat $(n=3)$ pancreatic and gut RNA were subjected to RT-PCR with the TCF/LEF and $\beta$-actin primers listed in Table 1. For $T c f>12$, the primers $6 \mathrm{~F}$ and $6 \mathrm{R}$ were used. Representative gels from three experiments are shown.

Finally, we isolated rat pancreatic islets. Approximately 400 islets were obtained from each rat $(n=4)$ and were evenly split into two parts and treated with or without insulin for $3 \mathrm{~h}$. Cells were collected and RNA was extracted for qRT-PCR. As shown in Fig. 6A, insulin treatment led to a 95, 85, and $90 \%$ reduction in the level of expression of $T c f 7, T c f 711$, and $T f f 712$ respectively. Figure $6 \mathrm{~B}$ shows that insulin treatment led to a significantly reduced expression of gcg, consistent with observation made by J Philippe two decades ago (Philippe 1989, 1991). Figure 6C shows that in the pancreas of HFD fed mice, the expression level of $T f f 7, T c f 711$, and $T f f 712$ was significantly lower than those from mice fed with chow diet.

Endogenous canonical Wnt signaling is not active in the pancreas

Considering the lack of abundant $T c f 7 l 2$ in the pancreas, we wondered whether the canonical Wnt signaling pathway is active in the pancreas of rodents. We used a transgenic mouse model, TOPGAL, for this study. In this model, the expression of the LacZ reporter is under the control of a Tcf/Lefresponsive promoter element. The expression of LacZ reporter would indicate canonical Wnt activity. Consistent with a recent report (Krutzfeldt \& Stoffel 2010), we cannot detect LacZ reporter activity in the pancreas of adult TOPGAL mice (data not shown). Figure 7A shows that in the neonatal TOPGAL mice, LacZ expression was not detectable in the pancreas (left panel), although it was detectable in the hair follicles of the mouse tail (right panel), liver, lung, and certain areas in the heart (data not shown). In the TOPGAL mice at an age of e $12 \cdot 5$, we still could not see appreciable LacZ expression in the area of pancreata (Fig. 7B).

\section{Discussion}

After the demonstration of a very strong association between the risk of T2D and specific polymorphisms in the TCF7L2 gene (Grant et al. 2006), this effector of Wnt signaling has drawn global attention (Florez et al. 2006, Munoz et al. 2006,
Scott et al. 2006, Cauchi et al. 2007, Dahlgren et al. 2007, Elbein 2007, Sladek et al. 2007, Jin 2008, Jin \& Liu 2008). How these single-nucleotide polymorphisms (SNPs) within intronic regions of the human TCF7L2 gene led to an increase in the risk of the development of T2D is unknown because it is difficult to assess whether these SNPs actually affect TCF7L2 expression levels. If these polymorphisms do affect TCF7L2 expression, then how mechanistically is this regulation achieved? Nevertheless, Prokunina-Olsson et al. $(2009 b)$ have reported very recently that the expression levels of two specific alternatively spliced forms of TCF7L2 mRNA in human pancreatic islets are expressed at relatively lower levels in individuals that carry the T2D-associated SNPs rs7903146 and rs12255372. Florez et al. (2006) found that these two TCF7L2 SNPs are associated with an increased risk of diabetes among subjects with impaired glucose tolerance. Lyssenko et al. (2007) reported that the T risk allele of SNP rs7903146 associates with impaired insulin secretion, incretin effects, and an increased rate of hepatic glucose production. They reported that TCF7L2 expression in human islets was increased fivefold in T2D patients, particularly in carriers of the TT genotype of the SNP rs7903146 (Lyssenko et al. 2007). Furthermore, overexpression of TCF7L2 in human islets reduced glucose-stimulated insulin secretion (Lyssenko et al. 2007). These observations, however, were contradicted by a later report by Shu et al. (2008) who claimed a beneficial effect of TCF7L2 on $\beta$-cell function from experiments with siRNA-mediated depletion, which suggested a role of TCF7L2 in the stimulation of $\beta$-cell proliferation and a
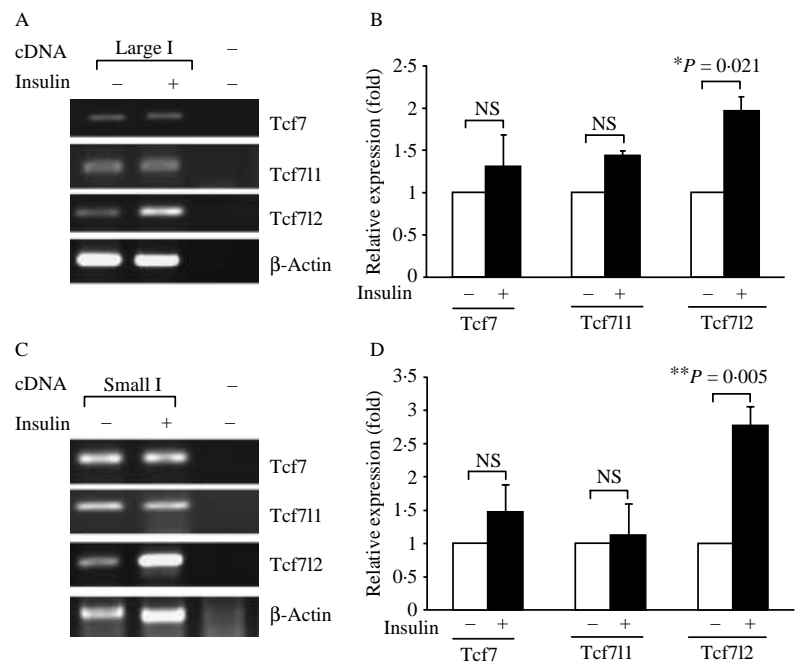

Figure 4 Insulin increases the expression of $T_{c} f>l 2$ but not the other two $T c f$ genes in the large and small intestines of the mouse. cDNAs from large $(A$ and $B)$ and small intestines $(C$ and $D)$ of 6 -week-old mouse $(n=3)$ treated with $100 \mathrm{nM}$ insulin $(3 \mathrm{~h})$ were subjected to (A and C) RT-PCR or (B and D) real-time qRT-PCR for assessing the expression of $T c f 7, T c f 7 / 1$, and $T c f 7 / 2$. For RT-PCR and qRT-PCR, $\beta$-actin was used as the internal control. RT-PCR gels are representatives of three independent experiments. qRT-PCR results are from three independent experiments, with triplicate samples per tissue from one mouse per experiment. ${ }^{*} P<0 \cdot 05 ;{ }^{* *} P<0 \cdot 01$. 

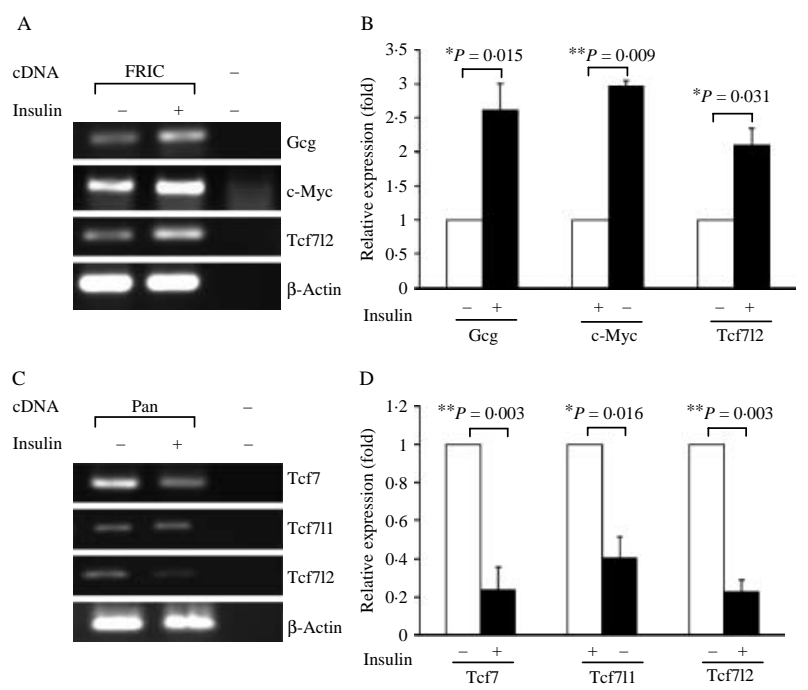

Figure 5 Insulin stimulates the expression of $T c f 7 / 2$ in FRIC cultures but represses the expression of Tcf genes in pancreas. (A and B) cDNAs from $100 \mathrm{nM}$ insulin-treated FRIC cultures $(3 \mathrm{~h})$ were subjected to (A) RT-PCR or (B) real-time RT-PCR for the detection of expression of gcg, $\mathrm{c}-\mathrm{Myc}$, and $T c f 7 / 2$. $\beta$-Actin was used as the internal control. Results are from three independent experiments. $(\mathrm{C}$ and $\mathrm{D}) \mathrm{cDNAs}$ from mouse pancreas $(n=3)$ treated with $100 \mathrm{nM}$ insulin (3 h) were subjected to (C) RT-PCR or (D) real-time RT-PCR for the detection of the expression of $T c f 7, T c f 7 / 1$, and $T c f>12$. Representative gels are from three independent experiments. qRT-PCR results are from three independent experiments, with triplicate samples per tissue. $\beta$-Actin was used as the normalizing control. ${ }^{*} P<0 \cdot 05 ;{ }^{* *} P<0 \cdot 01$.

reduction in $\beta$-cell apoptosis. Shu et al. (2009) also reported that in a T2D mouse model, Tff7l2 level was reduced instead of increasing, and this reduction was strongly associated with the reduced expression of the incretion hormone receptors, i.e. GLP1 receptor and GIP receptor. None of the above studies, however, have directly addressed the question of how mechanistically the TCF7L2 risk SNPs rendered individuals more susceptible to T2D. These studies, however, have re-directed our attention to the expression and function of Tcf7l2 and Wnt signaling in pancreatic islets, especially in the pancreatic $\beta$ cells.

Tcf712 is abundantly expressed in the mouse intestinal epithelia and adipocytes (Barker et al. 1999, Ross et al. 2000), and in the central nervous system (Lee et al. 2009). Inconsistent findings about $T_{c} f 712$ expression in the mouse pancreas, however, can be found in the literature. Yi et al. (2005) reported the failure to detect $T c f 712$ by an immunohistochemistry method in mouse pancreatic islets, which was consistent with previous reports by Korinek et al. (1998), Barker et al. (1999), and Duval et al. (2000a). Tof7l2 knockout mice or $T c f 712$ and $T c f 7$ double knockout mice showed a defect in gut development, but no abnormality was reported in the development of the pancreas (Korinek et al. 1998, Gregorieff et al. 2004). In this study, we show again the failure to detect $T f f 712$ expression by immunohistochemistry, although a low level of expression was detected by RT-PCR. It should be pointed out that in the pancreatic $\beta$-cell line Ins-1, Tcf7l2 expression level was comparable to that observed in the mouse gut and two intestinal cell lines. This observation is consistent with a recent report by Liu \& Habener (2008). We suggest that the abundant expression of Tof 712 in this cell line cannot be taken as evidence that this gene is abundantly expressed in primary pancreatic islets. Through our study of the alternatively spliced forms of $T \mathrm{cf} 712$ in this cell line, we were able to design a pair of primers for
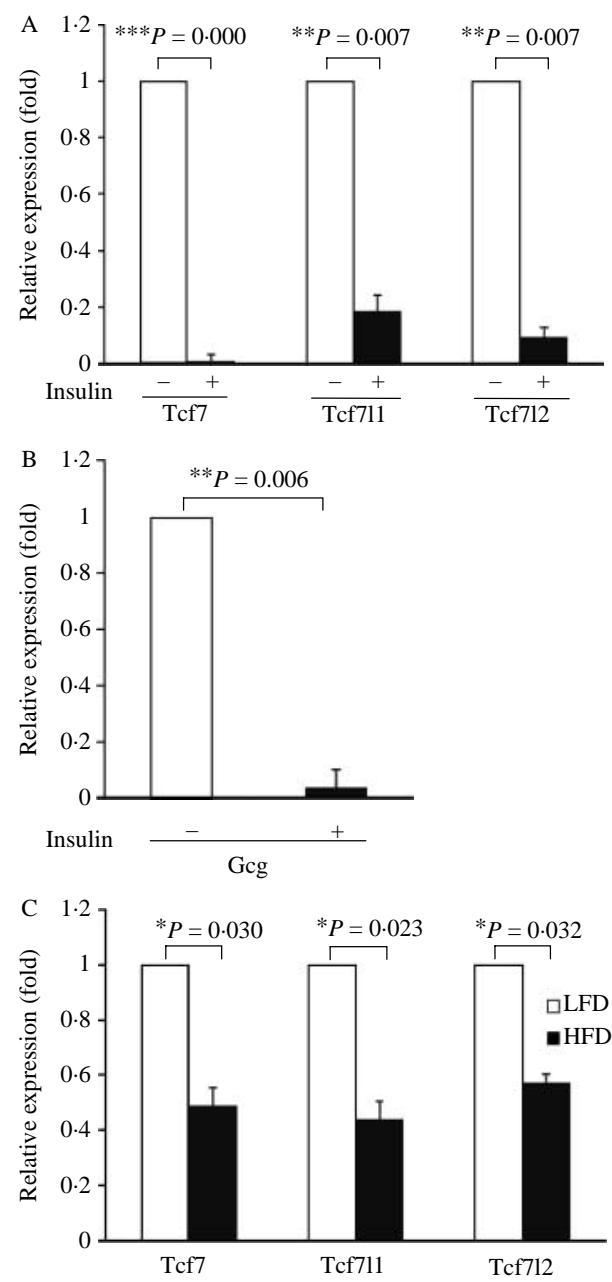

Figure $6 T c f$ gene expression in rat pancreatic islets is downregulated by insulin treatment or HFD feeding. Freshly isolated rat islet cells were treated with insulin $(100 \mathrm{nM})$ for $3 \mathrm{~h}$, followed by real-time RT-PCR for the detection of (A) Tcf7, Tcf7/1, and Tcf $7 / 2$ expressions or (B) gcg expression. $\beta$-Actin was used as the normalizing control. (C) HFD feeding leads to reduced Tcf gene expression. C57BL6 mice were fed with either HFD or chow diet for 2 months. The generation of hyperinsulinemia and insulin resistance by HFD feeding was monitored by serum insulin level and intravenous glucose tolerance test (data not shown). Pancreata were collected, and the expression of Tcf7, $T c f 711$, and $T c f 7 / 2$ was assessed by qRT-PCR. GAPDH was used as the normalizing control for qRT-PCR. ${ }^{*} P<0 \cdot 05 ;{ }^{* *} P<0 \cdot 01$; ${ }^{* * *} P<0 \cdot 001$. 


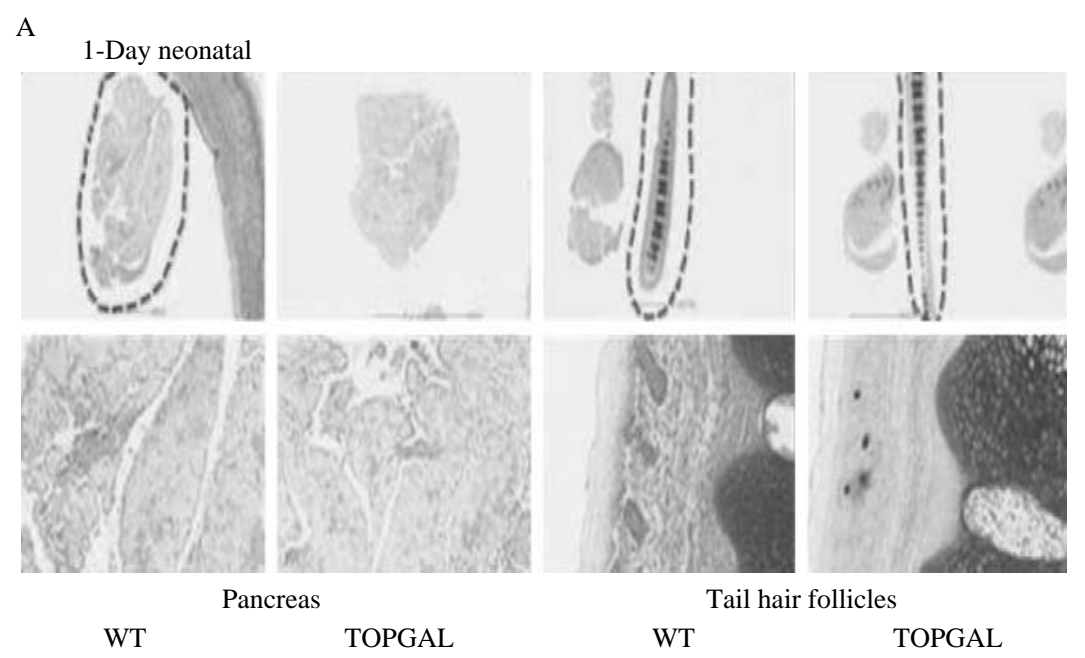

B $\quad$ e12.5

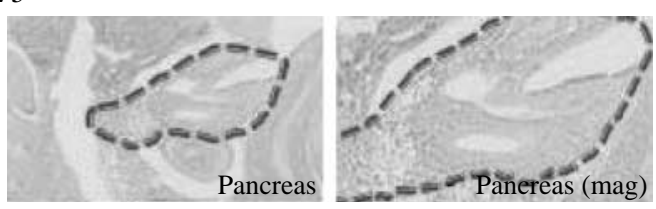

Figure 7 Cat/TCF-mediated LacZ expression is absent in the pancreas of TOPGAL mice. (A) No LacZ expression in the neonatal TOPGAL mouse pancreas, while the tail hair follicles show positive in LacZ staining. (B) No appreciable LacZ expression in the pancreata of TOPGAL mice at e12.5.

semi-quantitatively assessing Tcf7l2 expression level in the mouse pancreas. We show in this study that the Tcf 712 expression level in rodent pancreas is relatively low. This was further supported by observations in both western blotting and immunostaining.

The role of nuclear $\beta$-cat and the canonical Wnt signaling pathway in the development of pancreatic islets and the function of pancreatic $\beta$ cells have been documented recently in a number of transgenic mouse studies (Rulifson et al. 2007, Jin 2008, Jin \& Liu 2008), suggesting that pancreatic islet cells may express certain $T c f$ family members. We show in this study that in rodent pancreas and rat pancreatic islets, in addition to a low level of expression of $T c f 712$, mRNAs for two other $T c f$ family members, $T c f 7$ and $T c f 711$, were detectable. How these two Tcf proteins work with $\beta$-cat or other partners in mediating the effects of Wnt or other cell signaling pathways in pancreatic development and $\beta$-cell function deserves further investigation. In mice, it is possible that these $T c f$ members exert redundant functions since $T c f 7 l 2$ knockout mice and $T f f 7$ and $T f f 7 l 2$ double knockout mice show no detectable defect in pancreatic development (Korinek et al. 1998, Brinkmeier et al. 2007).

An important finding of the current study is that though in the gut and intestinal endocrine L-cells, Tcf 712 expression can be substantially stimulated by insulin, the expression of all three $T c f$ genes that are expressed in pancreatic islets was significantly repressed by insulin. The opposite effects of insulin on up- and downregulations of gcg expression in intestinal endocrine L-cells and pancreatic $\alpha$ cells respectively have been observed previously as well (Philippe 1991, Yi et al. 2005). The cell-type-specific response to insulin treatment is physiologically important, as the final active hormonal products of the pro-hormone, pro-glucagon, in pancreatic $\alpha$ cells and intestinal endocrine L-cells, exert opposite effects on blood glucose homeostasis. Interestingly, both insulin and lithium do not affect nuclear $\beta$-cat levels in a pancreatic $\alpha$-cell line (Yi et al. 2005). These observations, along with the lack of appreciable canonical Wnt activation in the TOPGAL mice (Krutzfeldt \& Stoffel 2010), made us wonder whether Tff7l2 or other TCF proteins can function as positive regulators of gene expression, independent of the participation of $\beta$-cat or of the formation of the bipartite transcription factor cat/TCF. If this is true, then our current view of the mechanistic function of Wnt signaling may have to change. At this stage, it is generally accepted that in the absence of $\beta$-cat, a TCF protein that binds to a downstream target gene promoter represses transcription through the recruitment of repressive partners (Jin \& Liu 2008).

TCF7L2 is also expressed in adipocytes. A previous study showed that insulin reduced the TCF7L2 expression level in cultured human adipocytes, which could be attenuated by the 
incubation of these cells with the free fatty acids palmitate or oleate (Ahlzen et al. 2008). An in vivo study by the same group showed a significantly higher level of TCF7L2 mRNA expression in subcutaneous adipose tissue in subjects with severe insulin resistance, although a correlation between TCF7L2 mRNA expression and extend of obesity could not be established (Ahlzen et al. 2008). Furthermore, adipocytederived Wnt signaling is able to stimulate insulin secretion and $\beta$-cell proliferation (Schinner et al. 2008). How the downregulation of TCF expression by insulin in both pancreatic islets and adipose tissue collectively contributes to the development of T2D deserves intensive investigation.

In conclusion, we demonstrate in this study that in rodent pancreas, $T f f 712$ expression level is relatively low, whereas the expression of the other two $T c f$ genes, $T c f 7$ and $T c f 7 l 1$, is detectable. The expression of these three genes can be downregulated by insulin or HFD feeding. The contribution of $T c f 7$ and $T c f 7 l 1$ to pancreatic development and function of $\beta$ cells is unknown and deserves further investigation. Since cat/TCF-mediated reporter gene activity is absent in adult (Krutzfeldt \& Stoffel 2010) and e12.5 pancreas, Tcf proteins may exert their biological functions by a mechanism that falls outside the scope of the narrowly defined canonical Wnt signaling pathway that uses TCF/LEF DNA-binding cis-elements.

\section{Supplementary data}

This is linked to the online version of the paper at http://dx.doi.org/10.1677/ JOE-10-0044.

\section{Declaration of interest}

The authors declare that there is no conflict of interest that could be perceived as prejudicing the impartiality of the research reported.

\section{Funding}

This study was supported by an operating grant from Canadian Institutes of Health Research (CIHR) to T J (MOP89987) and H Y G (MOP86544), a Natural Sciences and Engineering Research Council Discovery grant to D M I, and an operating grant from Canadian Diabetes Association to Q W (\#OG-3-07-2357). J C is a recipient of Banting and Best Diabetes Centre (BBDC)/University Health Network (UHN) Graduate Award. W S is a recipient of BBDC/UHN Fellowship (Diabetes Care). Q W is supported by CIHR New Investigator program.

\section{References}

Ahlzen M, Johansson LE, Cervin C, Tornqvist H, Groop L \& Ridderstrale M 2008 Expression of the transcription factor 7-like 2 gene (TCF7L2) in human adipocytes is down regulated by insulin. Biochemical and Biophysical Research Communications 370 49-52. (doi:10.1016/j.bbrc.2008.03.006)

Barker N, Huls G, Korinek V \& Clevers H 1999 Restricted high level expression of Tcf-4 protein in intestinal and mammary gland epithelium. American Journal of Pathology 154 29-35.
Brinkmeier ML, Potok MA, Davis SW \& Camper SA 2007 TCF4 deficiency expands ventral diencephalon signaling and increases induction of pituitary progenitors. Developmental Biology 311 396-407. (doi:10.1016/j.ydbio. 2007.08.046)

Cauchi S, El Achhab Y, Choquet H, Dina C, Krempler F, Weitgasser R, Nejjari C, Patsch W, Chikri M, Meyre D et al. 2007 TCF7L2 is reproducibly associated with type 2 diabetes in various ethnic groups: a global meta-analysis. Journal of Molecular Medicine 85 777-782. (doi:10. 1007/s00109-007-0203-4)

Dahlgren A, Zethelius B, Jensevik K, Syvanen AC \& Berne C 2007 Variants of the TCF7L2 gene are associated with beta cell dysfunction and confer an increased risk of type 2 diabetes mellitus in the ULSAM cohort of Swedish elderly men. Diabetologia 50 1852-1857. (doi:10.1007/s00125007-0746-5)

Drucker DJ, Jin T, Asa SL, Young TA \& Brubaker PL 1994 Activation of proglucagon gene transcription by protein kinase-A in a novel mouse enteroendocrine cell line. Molecular Endocrinology 8 1646-1655. (doi:10. 1210/me.8.12.1646)

Duval A, Busson-Leconiat M, Berger R \& Hamelin R 2000a Assignment of the TCF-4 gene (TCF7L2) to human chromosome band 10q25.3. Cytogenetics and Cell Genetics 88 264-265. (doi:10.1159/000015534)

Duval A, Rolland S, Tubacher E, Bui H, Thomas G \& Hamelin R $2000 b$ The human T-cell transcription factor-4 gene: structure, extensive characterization of alternative splicings, and mutational analysis in colorectal cancer cell lines. Cancer Research $603872-3879$.

Elbein SC 2007 Evaluation of polymorphisms known to contribute to risk for diabetes in African and African-American populations. Current Opinion in Clinical Nutrition and Metabolic Care 10 415-419. (doi:10.1097/MCO. 0b013e3281e2c99a)

Florez JC, Jablonski KA, Bayley N, Pollin TI, de Bakker PI, Shuldiner AR, Knowler WC, Nathan DM \& Altshuler D 2006 TCF7L2 polymorphisms and progression to diabetes in the Diabetes Prevention Program. New England Journal of Medicine 355 241-250. (doi:10.1056/NEJMoa062418)

Grant SF, Thorleifsson G, Reynisdottir I, Benediktsson R, Manolescu A, Sainz J, Helgason A, Stefansson H, Emilsson V, Helgadottir A et al. 2006 Variant of transcription factor 7-like 2 (TCF7L2) gene confers risk of type 2 diabetes. Nature Genetics 38 320-323. (doi:10.1038/ng1732)

Gregorieff A, Grosschedl R \& Clevers H 2004 Hindgut defects and transformation of the gastro-intestinal tract in Tcf4 $(-/-) / \mathrm{Tcf1}(-/-)$ embryos. EMBO Journal 23 1825-1833. (doi:10.1038/sj.emboj.7600191)

He TC, Sparks AB, Rago C, Hermeking H, Zawel L, da Costa LT, Morin PJ, Vogelstein B \& Kinzler KW 1998 Identification of c-MYC as a target of the APC pathway. Science 281 1509-1512. (doi:10.1126/science.281. 5382.1509)

Jin T 2008 The WNT signalling pathway and diabetes mellitus. Diabetologia $\mathbf{5 1}$ 1771-1780. (doi:10.1007/s00125-008-1084-y)

Jin T \& Drucker DJ 1996 Activation of proglucagon gene transcription through a novel promoter element by the caudal-related homeodomain protein cdx-2/3. Molecular and Cellular Biology 16 19-28.

Jin T \& Liu L 2008 The Wnt signaling pathway effector TCF7L2 and type 2 diabetes mellitus. Molecular Endocrinology 22 2383-2392. (doi:10.1210/me. 2008-0135)

Jin T, George Fantus I \& Sun J 2008 Wnt and beyond Wnt: multiple mechanisms control the transcriptional property of beta-catenin. Cellular Signalling 20 1697-1704. (doi:10.1016/j.cellsig.2008.04.014)

Kinzler KW \& Vogelstein B 1996 Lessons from hereditary colorectal cancer. Cell 87 159-170. (doi:10.1016/S0092-8674(00)81333-1)

Kirchhoff K, Machicao F, Haupt A, Schafer SA, Tschritter O, Staiger H, Stefan N, Haring HU \& Fritsche A 2008 Polymorphisms in the TCF7L2, CDKAL1 and SLC30A8 genes are associated with impaired proinsulin conversion. Diabetologia 51 597-601. (doi:10.1007/s00125008-0926-y)

Korinek V, Barker N, Moerer P, van Donselaar E, Huls G, Peters PJ \& Clevers H 1998 Depletion of epithelial stem-cell compartments in the small intestine of mice lacking Tcf-4. Nature Genetics 19 379-383. (doi:10.1038/1270) 
Krutzfeldt J \& Stoffel M 2010 Regulation of wingless-type MMTV integration site family (WNT) signalling in pancreatic islets from wild-type and obese mice. Diabetologia 53 123-127. (doi:10.1007/s00125009-1578-2)

Lee S, Lee CE, Elias CF \& Elmquist JK 2009 Expression of the diabetesassociated gene TCF7L2 in adult mouse brain. Journal of Comparative Neurology 517 925-939. (doi:10.1002/cne.22199)

Liu Z \& Habener JF 2008 Glucagon-like peptide-1 activation of TCF7L2dependent Wnt signaling enhances pancreatic beta cell proliferation. Journal of Biological Chemistry 283 8723-8735. (doi:10.1074/jbc. M706105200)

Lyssenko V, Lupi R, Marchetti P, Del Guerra S, Orho-Melander M, Almgren P, Sjogren M, Ling C, Eriksson KF, Lethagen AL et al. 2007 Mechanisms by which common variants in the TCF7L2 gene increase risk of type 2 diabetes. Journal of Clinical Investigation 117 2155-2163. (doi:10.1172/ JCI30706)

Munoz J, Lok KH, Gower BA, Fernandez JR, Hunter GR, Lara-Castro C, De Luca M \& Garvey WT 2006 Polymorphism in the transcription factor 7-like 2 (TCF7L2) gene is associated with reduced insulin secretion in nondiabetic women. Diabetes 55 3630-3634. (doi:10.2337/ db06-0574)

Philippe J 1989 Glucagon gene transcription is negatively regulated by insulin in a hamster islet cell line. Journal of Clinical Investigation 84 672-677. (doi:10.1172/JCI114214)

Philippe J 1991 Insulin regulation of the glucagon gene is mediated by an insulin-responsive DNA element. PNAS 88 7224-7227. (doi:10.1073/ pnas.88.16.7224)

Prokunina-Olsson L, Kaplan LM, Schadt EE \& Collins FS 2009a Alternative splicing of TCF7L2 gene in omental and subcutaneous adipose tissue and risk of type 2 diabetes. PLoS ONE 4 e7231. (doi:10.1371/journal.pone. 0007231)

Prokunina-Olsson L, Welch C, Hansson O, Adhikari N, Scott LJ, Usher N, Tong M, Sprau A, Swift A, Bonnycastle LL et al. $2009 b$ Tissue-specific alternative splicing of TCF7L2. Human Molecular Genetics 18 3795-3804. (doi:10.1093/hmg/ddp321)

Ross SE, Hemati N, Longo KA, Bennett CN, Lucas PC, Erickson RL \& MacDougald OA 2000 Inhibition of adipogenesis by Wnt signaling. Science 289 950-953. (doi:10.1126/science.289.5481.950)

Rulifson IC, Karnik SK, Heiser PW, ten Berge D, Chen H, Gu X, Taketo MM, Nusse R, Hebrok M \& Kim SK 2007 Wnt signaling regulates pancreatic beta cell proliferation. PNAS 104 6247-6252. (doi:10.1073/pnas.0701509104)

Schafer SA, Tschritter O, Machicao F, Thamer C, Stefan N, Gallwitz B, Holst JJ, Dekker JM, t'Hart LM, Nijpels G et al. 2007 Impaired glucagon-like peptide-1-induced insulin secretion in carriers of transcription factor 7-like 2 (TCF7L2) gene polymorphisms. Diabetologia 50 2443-2450. (doi:10.1007/s00125-007-0753-6)

Schinner S, Ulgen F, Papewalis C, Schott M, Woelk A, Vidal-Puig A \& Scherbaum WA 2008 Regulation of insulin secretion, glucokinase gene transcription and beta cell proliferation by adipocyte-derived Wnt signalling molecules. Diabetologia 51 147-154. (doi:10.1007/s00125-007-0848-0)
Scott LJ, Bonnycastle LL, Willer CJ, Sprau AG, Jackson AU, Narisu N, Duren WL, Chines PS, Stringham HM, Erdos MR et al. 2006 Association of transcription factor 7-like 2 (TCF7L2) variants with type 2 diabetes in a Finnish sample. Diabetes 55 2649-2653. (doi:10.2337/db06-0341)

Shiina H, Igawa M, Breault J, Ribeiro-Filho L, Pookot D, Urakami S, Terashima M, Deguchi M, Yamanaka M, Shirai M et al. 2003 The human T-cell factor-4 gene splicing isoforms, Wnt signal pathway, and apoptosis in renal cell carcinoma. Clinical Cancer Research 9 2121-2132.

Shu L, Sauter NS, Schulthess FT, Matveyenko AV, Oberholzer J \& Maedler K 2008 Transcription factor 7-like 2 regulates beta-cell survival and function in human pancreatic islets. Diabetes 57 645-653. (doi:10.2337/db07-0847)

Shu L, Matveyenko AV, Kerr-Conte J, Cho JH, McIntosh CH \& Maedler K 2009 Decreased TCF7L2 protein levels in type 2 diabetes mellitus correlate with downregulation of GIP- and GLP-1 receptors and impaired beta-cell function. Human Molecular Genetics 18 2388-2399. (doi:10.1093/hmg/ddp178)

Sirek AS, Liu L, Naples M, Adeli K, Ng DS \& Jin T 2009 Insulin stimulates the expression of carbohydrate response element binding protein (ChREBP) by attenuating the repressive effect of Pit-1, Oct-1/Oct-2, and Unc-86 homeodomain protein octamer transcription factor-1. Endocrinology 150 3483-3492. (doi:10.1210/en.2008-1702)

Sladek R, Rocheleau G, Rung J, Dina C, Shen L, Serre D, Boutin P, Vincent D, Belisle A, Hadjadj S et al. 2007 A genome-wide association study identifies novel risk loci for type 2 diabetes. Nature 445 881-885. (doi:10.1038/nature05616)

Sun J, Khalid S, Rozakis-Adcock M, Fantus IG \& Jin T 2009 P21 -activated protein kinase-1 functions as a linker between insulin and Wnt signaling pathways in the intestine. Oncogene 28 3132-3144. (doi:10.1038/onc.2009.167)

Sun J, Wang D \& Jin T 2010 Insulin alters the expression of components of the Wnt signaling pathway including TCF-4 in the intestinal cells. Biochimica et Biophysica Acta 1800 344-351. (doi:10.1016/j.bbagen.2009.12.007)

Wang Q \& Brubaker PL 2002 Glucagon-like peptide-1 treatment delays the onset of diabetes in 8 week-old db/db mice. Diabetologia 45 1263-1273. (doi:10.1007/s00125-002-0828-3)

Wang P, Wang Q, Sun J, Wu J, Li H, Zhang N, Huang Y, Su B, Li RK, Liu L et al. 2009 POU homeodomain protein Oct-1 functions as a sensor for cyclic AMP. Journal of Biological Chemistry 284 26456-26465. (doi:10.1074/ jbc.M109.030668)

Yi F, Brubaker PL \& Jin T 2005 TCF-4 mediates cell type-specific regulation of proglucagon gene expression by beta-catenin and glycogen synthase kinase-3beta. Journal of Biological Chemistry 280 1457-1464. (doi:10.1074/ jbc.M411487200)

Yi F, Sun J, Lim GE, Fantus IG, Brubaker PL \& Jin T 2008 Cross talk between the insulin and Wnt signaling pathways: evidence from intestinal endocrine L cells. Endocrinology 149 2341-2351. (doi:10.1210/en.2007-1142)

Received in final form 6 July 2010

Accepted 22 July 2010

Made available online as an Accepted Preprint 30 July 2010 